\title{
ANÁLISE CRÍTICA DO PROCESSO DE MODERNIZAÇÃO DO MODELO DE INTEGRAÇÃO DO MERCADO COMUM DO SUL (MERCOSUL)
}

\author{
Manoel Coracy Saboia Dias ${ }^{1}$ \\ Leonardo Mèrcher ${ }^{2}$
}

\begin{abstract}
RESUMO
Este artigo tem como objeto analisar criticamente o processo de modernização do modelo de integração do Mercado Comum do Sul (MERCOSUL). A literatura acumulada sobre o MERCOSUL tem abordado as diferentes facetas desse processo de integração - econômica, política, social e jurídica - e tem contribuído para uma compreensão razoável do que foi o bloco em sua origem, como ele evoluiu ao longo das duas primeiras décadas e sobre quais são seus principais problemas e mudança de paradigmas na política externa do Brasil. Quanto às opções teóricas (marco de referência e conceitual), metodológicas e recortes, este trabalho por ser eminentemente bibliográfico, tem como fulcro os estudos explanatórios, que podem ser utilizados para investigar sobre alguns temas com base em novas perspectivas e ampliar os estudos já existentes, bem como os diplomas legais do MERCOSUL, que auxilia a construção teórica e ao mesmo tempo a reconstrução crítica dos seus fundamentos. Infere-se dessas opções o marco de referência e conceitual, no qual há pelo menos cinco interpretações com forte poder explicativo das causas da crise, com vistas a formulação e concretização de um conjunto de medidas de diversas ordens para acelerar o processo de modernização do modelo de integração do MERCOSUL. Os resultados deste artigo corroboram a hipótese segundo qual o MERCOSUL encontra-se no estágio de União Aduaneira (imperfeita), havendo necessidade de ajustes à realidade em que se vive, com vistas a resgatar o projeto inicial e incentivo aos acordos com outros Estados e blocos.
\end{abstract}

Palavras-chave: MERCOSUL. Processo de Modernização. Análise Crítica.

\footnotetext{
${ }^{1}$ Bacharelado (em andamento) em Relações Internacionais pelo Centro Universitário Internacional UNINTER (2015). Bacharelado (em andamento) em Ciência Política pelo Centro Universitário Internacional - UNINTER (2017). Licenciado Pleno em Filosofia pela Universidade Federal do Pará (Belém, PA, BRASIL, 1983-1986). Bacharel em Filosofia pela Universidade Federal do Pará (Belém, PA, BRASIL, 1987-1990), Bacharel em Direito pela Faculdade da Amazônia Ocidental (Rio Branco, AC, BRASIL, 2005-2010). Especialista em Filosofia Política pela Faculdade de Teologia e Filosofia Sinal (Rio Branco, AC, BRASIL, 2006 - 2007). Especialista em Psicopedagogia pela Faculdade de Educação Acriano Euclides da Cunha (Rio Branco, AC, BRASIL, 2009 - 2010). Especialização em Master in Business Administration em Gestão Pública, com ênfase em Controle Externo, pela Faculdade Internacional de Curitiba (FACINTER, Grupo UNINTER, 2009 - 2011). Mestrado (em andamento) em Direito pela Universidade de Brasília (UnB) (Mestrado Interinstitucional em Direito - Universidade de Brasília/Universidade Federal do Acre) (2015-2017). Doutorado (em andamento) em Filosofia da Universidade de São Paulo (USP) (2017). Professor Adjunto 4 da Universidade Federal do Acre, lotado no Centro de Filosofia e Ciências Humanas, em Rio Branco (AC), admitido por concurso público, em 03 de julho de 1989.
}

2 Doutor em Ciência Política (UFPR, 2016) com Bacharelado (2006) e Especialização (2009) em Relações Internacionais Contemporâneas pela PUC-Rio. Também possui Licenciatura (CEUCLAR, 2014) e. Bacharelado (EMBAP, 2015) em Belas Artes e Licenciatura em Biologia (CEUCLAR, 2016), além de Especialização em Comunicação, Cultura e Arte (2011) e em História Social da Arte (2011) pela PUC-PR. Voluntário do Centro de Informações das Nações Unidas, pertencente ao Secretariado Geral da ONU (2004-05) no Palácio Itamaraty. Analista Internacional no Consulado Geral dos EUA, Rio de Janeiro (2005-2007). Professor Pesquisador associado ao Núcleo de Pesquisa em Relações Internacionais (NEPRI/UFPR, 2011-presente) e fundador do periódico científico Conjuntura Global (UFPR, 2012) no qual foi Editor Executivo (2012-2015). Professor Universitário em Artes e Relações Internacionais desde 2009, integrando o corpo docente UNINTER em 2013. Atualmente é professor vinculado aos cursos superiores de Ciência Política, Relações Internacionais, Artes Visuais, Comércio Exterior, Gestão Pública e Secretariado Executivo Trilíngue. 


\section{INTRODUÇÃO}

A atual composição política da América foi resultado de mudanças políticas e econômicas ocorridas nos quinhentos anos: 35 (trinta e cinco) Estados independentes, 19 (dezenove) territórios dependentes de Estados europeus e/ou americanos e oito (oito) territórios integrados totalmente em países que não se situam na América (mas, sim, na Europa), e que, por isso, não são considerados territórios dependentes.

Essas unidades políticas têm vivido historicamente uma disparidade de processos de desenvolvimento econômico, entendidos como muitos variados processos de integração política entre si desde projetos de integração eminentemente geográficos e político-culturais a meramente econômicos.

Alguns são puramente americanos (OEA), norte-americanos (TLC da América do Norte), sul-americanos (MERCOSUL, UNASUL), latino-americanos (ALADI, CELAC), hemisférica (ALCA), sem abandonar o território físico do continente americano (Cf. GARRABELLI, 2004; GARCIA JUNIOR, 2004, 2007; MACHADO, 2012; CUNHA, 2017; BOHLKE, 2006; LARRAÑAGA, 2002; MENEM, 1996; LABRANO, 1998; JARDEL; BARRAZA, 1998; GONZALEZ-OLDEKOP, 1997; DROMI; EKMEKDJIAN; RIVERA, 1996; LEAL et al. 2001; SEITENFUS, 2013; DOMINGUES; OLIVEIRA, 2017).

Outros transcendem as fronteiras americanas e vão mais além, pois existem organizações que são hispano-americanas (ASALE), ibero-americanas (Cúpula lberoamericana, OEI), ao mesmo tempo em que se abrem novos termos que poderiam dar lugar a formas de integração desconhecidas hoje em dia (Iberofonia, lusofonia).

O MERCOSUL, notadamente, é formado por Brasil, Argentina, Paraguai e Uruguai. Chile, Bolívia, Colômbia, Equador, Peru, Guiana e Suriname são Estados associados. Em 2006, a Venezuela solicitou a entrada no bloco como Estado-Parte, o que se concretizou em 2012, mas, foi suspensa em dezembro de 2016. São Estados observadores: México e Nova Zelândia.

A diferença entre Estados-Parte e Estado Associados ao MERCOSUL está na adesão da Tarifa Externa Comum (TEC). A TEC é adotada apenas pelos EstadosParte, porque são os responsáveis pelas principais decisões, incluindo a aprovação do ingresso de novos Estados-Parte (Cf. MACHADO, 2012). 
Os processos de integração podem assumir vários formatos, que dependem da conjuntura internacional e do contexto regional, de um modo geral, pode-se registrar as seguintes características dos distintos níveis de integração econômica (Cf. GARCIA JÚNIOR, 2004; DOMINGUES; OLIVEIRA, 2017):

a) Zona de preferência tarifária: dois ou mais Estados soberanos negociam entre si listas de itens que gorarão de reduções nas alíquotas dos impostos de importação incidentes. Com o estabelecimento de uma zona de preferência tarifária, os bens, produtos e mercadorias expressamente indicados pelos governos dos países envolvidos gorarão de uma redução especial nas alíquotas dos impostos de importação sobre eles incidentes. Assim, ingressarão com preços mais baixos ao mercado importador;

b) Zona de livre comércio ou área de livre comércio: eliminação de barreiras tarifárias e não-tarifárias ao comércio internacional praticado pelos Estados envolvidos (1). Os Estados participantes continuam a praticar livremente o comércio internacional com terceiros Estados, fixando suas alíquotas nas tarifas aduaneiras. Com a situação de desgravação tributaria privilegiada ocorre em relação aos Estados participantes e não com relação a terceiros Estados - mister a criação de regras de origem para diferenciar produtos intra e extrazona;

c) União Aduaneira: (1) + adoção de uma tarifa externa comum relação a terceiros Estados (2). Nessa fase, os Estados procuram evitar disparidades tributárias, ao menos no que concerne às alíquotas dos impostos de importação. Sem o estabelecimento da TEC ocorreriam desvios de comércio, com produtos extrazona ingressando no território do Estado participante com menos alíquota de imposto de importação e, mediante o processo vulgarmente denominado de "maquiagem", ingressar no território dos demais Estados participantes, como "nacional", gozando da desgravação tarifária;

d) Mercado Comum: (1) + (2) + políticas de convergência entre todos os Estados envolvidos (3) + livre circulação dos demais fatores de produção (capital e trabalho/mão-de-obra) (4), e) União política e econômica: $(1)+(2)+(3)+(4)+$ adoção de sistema monetário comum (5);

f) Confederação: $(1)+(2)+(3)+(4)$ + constituição confederativa + legislação parcialmente unificada (normas de âmbito espacial de incidência abrangentes de todos os Estados independentes reunidos/Estados confederados) + sistemas de defesa e de política externa comum. 
A escolha deste tema justifica-se em razão do Mercado Comum do Sul (MERCOSUL), criado mediante o Tratado de Assunção, em março de 1991, que deveria estar estabelecido a 31 de dezembro de 1994, implicaria nos seguintes termos: a livre circulação de bens serviços e fatores produtivos entre os países, através, entre outros, da eliminação dos direitos alfandegários restrições não tarifárias à circulação de mercado de qualquer outra medida de efeito equivalente; o estabelecimento de uma tarifa externa comum e a adoção de uma política comercial comum em relação a terceiros Estados ou agrupamentos de Estados e a coordenação de posições em foros econômico-comerciais regionais e internacionais; a coordenação de políticas macroeconômicas e setoriais entre os Estados Partes - de comércio exterior, agrícola, industrial, fiscal, monetária, cambial e de capitais, de serviços, alfandegária, de transportes e comunicações e outras que se acordem -, a fim de assegurar condições adequadas de concorrência entre os Estados Partes; e o compromisso dos Estados Partes de harmonizar suas legislações, nas áreas pertinentes, para lograr o fortalecimento do processo de integração (Art. $1^{\circ}$ ); contudo, ainda se encontra no estágio de uma união aduaneira imperfeita (GARCIA JUNIOR, 2004), ou seja, apesar do nome, o Mercado Comum do Sul é uma união aduaneira imperfeita, tendo em vista as sucessivas negociações de listas de exceções (pelos países envolvidos) cujos itens ficariam fora do programa de desgravação tarifária previsto para chegar a alíquota zero em 30 de dezembro de 1994, cujos prazos originários de expiração eram para a Argentina e Brasil até 31 de dezembro de 1994 e Paraguai e Uruguai até 31 de dezembro de 1995 (Cf. GARCIA JUNIOR, 2004, p. 52-53). Por conseguinte, "quando não mais restar itens excluídos, poder-se-á dizer que o MERCOSUL atingiu sua fase de união aduaneira perfeita. Obviamente, o levantamento de barreira não tarifárias também é imprescindível para a caracterização do espaço" (GARCIA JUNIOR, 2004, p. 53).

Diante desse quadro, o presente trabalho no afã de analisar criticamente a modernização dos modelos de integração regional, notadamente, o Mercado Comum do Sul (MERCOSUL), tem a intenção de responder a uma série de perguntas, a saber: como se integram Estados tão díspares entre si? O desenvolvimento é um freio ou um impulso à integração? Os Estados da América hão de se integrar entre si ou hão de transcender o continente americano em integrações transamericanas? Por que o MERCOSUL não se consolidou nos anos noventa? Em que sentido as instituições de cooperação econômica no Cone Sul não convergem para o desenvolvimento do 
MERCOSUL? A implementação da ALCA seria um obstáculo para a consolidação do MERCOSUL? O desenvolvimento, consolidação e modernização do MERCOSUL dependem do fortalecimento político, entre outros fatores, de seus Estados-Parte?

Por conseguinte, em função da problematização, justificativa e questões e perguntas, o objetivo geral deste trabalho consiste em analisar criticamente 0 processo de modernização do modelo de integração do Mercado Comum do Sul (MERCOSUL). Como objetivos específicos, para alcançar o objetivo geral, primeiramente, avaliar-se-á a formação da ALALC e ALADI nos anos sessenta. $\mathrm{Na}$ sequência, buscar-se-á identificar as características positivas e negativas do Tratado de Assunção, Protocolo de Ouro Preto, Protocolo de Olivos e demais diplomas legais e suas eficácias. Finalmente, analisar-se-á o processo de modernização do processo de integração do MERCOSUL.

A hipótese que norteia este trabalho para que se se posa atingir os objetivos é a seguinte: por considerar que o MERCOSUL se encontra no estágio de União Aduaneira (imperfeita), há necessidade de analisar criticamente o seu processo de modernização: ajustes à realidade em que se vive, resgate o projeto inicial e incentivo aos acordos com outros Estados e blocos.

Quanto às opções metodológicas e recortes, este trabalho por ser eminentemente bibliográfico, tem como fulcro os estudos explanatórios (Vide Referencias), que podem ser utilizados para investigar sobre alguns temas com base em novas perspectivas e ampliar os estudos já existentes, bem como os diplomas legais do MERCOSUL, que auxilia a construção teórica e ao mesmo tempo a reconstrução crítica dos seus fundamentos.

Infere-se dessas opções o marco de referência e conceitual, no qual há pelo menos cinco interpretações com forte poder explicativo das causas da crise (mas, não exclusivamente), com vistas a formulação e concretização de um conjunto de medidas de diversas ordens para acelerar o processo de modernização do modelo de integração do MERCOSUL.

Por fim, o presente trabalho está estruturado em três partes, inclusive esta introdução e a conclusão, a saber: processos de integração inter-regionais: ALALC e ALADI; o Tratado de Assunção, Protocolo de Ouro Preto e o Protocolo De Olivos: criação, estrutura e desenvolvimento do MERCOSUL; e o processo de modernização do processo de integração do MERCOSUL. 
1 PROCESSOS DE INTEGRAÇÃO INTER-REGIONAIS: ASSOCIAÇÃO LATINOAMERICANO A DE LIVRE COMÉRCIO (ALAC) E ASSOCIAÇÃO LATINAAMARICANA DE INTEGRAÇÃO (ALADI) ${ }^{3}$

Atualmente, a decisão de estabelecer processos de integração regional é motivada pela obtenção de ganhos com o livre comércio no âmbito de alcance dos países e na cooperação internacional entre eles (FERREIRA; MERCHER, 2015, p. 218).

No entanto, na América Latina, ocorreram vários processos de integração regional, principalmente derivados de interesses políticos e econômicos. A Associação Latino-Americana de Livre comércio (ALALC) foi a primeira iniciativa de integração concretizada. Apesar dos conflitos, na década de 1970, a ALAC se expandiu e nos membros aderiram a ela, como Bolívia, Colômbia, Equador e Venezuela. Essa expansão levou a uma nova configuração da associação, que passou a chamar-se Associação Latino-Americana de Integração (ALADI) e atualmente é a maior associação de países com o maior número de membros da América latina, contando com 12 Estados-membros. No final da década de 19780, surgiu o Pacto Andino, atual comunidade Andina de Nações (CAN). Seguindo esse modelo, e, 1973 foi instituída a Comunidade do Caribe (CARICOM). Nos anos 1990, no contexto pós-Consenso de Washington, surgiam novas iniciativas de integração regional de caráter econômico nas Américas. O Tratado Norte-Americano de Livre Comércio (NAFTA), formado por Estados Unidos, México e Canadá, e - o Mercado Comum do Sul (MERCOSUL, com a Argentina, Brasil, Paraguai, Uruguai e Venezuela, completam o cenário de integração regional da região (Cf. FERREIRA; MERCHER, 2015, p. 220-222).

Argentina, Brasil, Chile e Uruguai e Comissão Econômica para a América Latina (CEPAL), promoveram a ideia de instituir um acordo para a constituição de uma área de livre comércio de implantação gradual e seletiva com o fim último de constituir um Mercado Comum Latino-Americano (Cf. GARABELLI, 2004, p.83).

Após desenvolver uma série de negociações, os governos da Argentina, Brasil, Chile, México, Paraguai, Peru e Uruguai subscreveram em fevereiro de 1960, um tratado que estabelece e uma zona de livre comércio e institui a Associação Latino-

\footnotetext{
${ }^{3}$ Cf. GARCIA, 2005.
} 
Americana de Livre Comércio, cuja sede é a cidade de Montevidéu. Posteriormente aderiram ao acordo, Bolívia, Colômbia, Equador e Venezuela (Cf. GARABELLI, 2004, p. 83).

Situações de índole diversa fizeram com que a ALALC levasse um ritmo muito lento em seu processo degradante. Assim mesmo surgiu um grande desanimo entre os países de menor desenvolvimento relativo em relação as expectativas iniciais. Concorda-se então na necessidade de modificação da ALAC buscando que seja mais realista e flexível. Em 1978, a Conferencia da ALAC por meio da Resolução 370, encarrega o Comitê Executivo Permanente a realização de trabalhos preparatórios para a reestruturação da ALAC (Cf. GARABELLI, 2004, p. 84).

Como consequência do ocorrido, o Conselho de Ministros firma um novo Tratado de Montevidéu em 123 de agosto de 1980 (TM80), que conforme reza seu preambulo, substitui o Trateado constitutivo de ALAC de 1960 (Cf. GARABELLI, 2004, p. 84).

Nasce, então, a Associação Latino-Americana de Integração (ALADI), novo organismo intergovernamental que promove a expansão da integração da região, com o fim de assegurar seu desenvolvimento econômico e social, e com o objetivo último de estabelecer um mercado comum (cf. GARRABELLI, 2004, p. 84).

Foram seus membros originários os mesmos integrantes da ALALC: Argentina, Bolívia, Brasil, Chile, Colômbia, Equador, México, Paraguai, Peru, Uruguai e Venezuela. Cuba que teria status de observador desde 1986, ingressou como membro pleno da Associação por acordo unanime dos Estados membros em 1998 (Cf. GARABELLI, 2004, p. 84-85).

Portanto, a ALALC e ALADI, significam um importante antecedente do MERCOSUL, mas, se estudarmos as ações imediatas que desembocaram diretamente na formação do bloco, devemos admitir que determinadas circunstancias vinculadas com a instalação dos processos democráticos nos países do Cone Sul e as relações entre Argentina e Brasil, constituem dois cimentos deste processo de integração (GARABELLI, 2004, p. 110). 


\section{O tRATAdo de ASSUnçÃo, PROTOCOLO DE OURO PRETO E O PROTOCOLO DE OLIVOS: CRIAÇÃO, ESTRUTRURA E DESENVOLVIMENTO DO MERCOSUL ${ }^{4}$}

\subsection{TRATADO DE ASSUNÇÃO}

O Tratado de Assunção é um marco normativo, firmado pelos governos da Argentina, Brasil, Paraguai e Uruguai em 26 de março de 1991. Em razão deste Tratado, os Estados-Partes decidem construir um Mercado Comum, que deveria estar formado em 31 de dezembro de 1994, e que se denominaria "Mercado Comum do Sul" (MERCOSUL). São signatários do Tratado de Assunção pelo Governo da Republica Argentina, o Presidnte Carlos Saul Menem e o Chanceler Guido Di Tella; pelo Governo da Republica Federativa do Brasil, o Presidente Fernando Collor de Melo e o Chanceler Francisco Rezek; pelo Governo da Republica do Paraguai, o Presidente Andrés Rodríguez e o Chanceler Alexis Frutos Vaesken; e pelo Governo da Republica Oriental do Uruguai, o Presidente Alberto Lacalle Herrera e o Chanceler Héctor Gros Espiell.

O Tratado de Assunção foi internalizado na República Federativa do Brasil pelo Decreto 350, de 21 de novembro de 1991, D.O.U., de 22 de setembro de 1991, aprovado pelo Decreto Legislativo 197, de 25 de setembro de 1991, D.O.U., de 26 de setembro de 1991, com Carta de ratificação depositada pelo Brasil em 30 de outubro de 1991, já então com a adesão do Paraguai e Uruguai, entra em vigor em 29 de novembro de 1991.

A República Argentina o ratificou o legislativamente por meio da Lei n. 23.981, de 15 d agosto de 1991, efetuando-se o depósito em 20 de outubro de 1991. A República do Paraguai o aprovou por meio da Lei n. 9, de 30 de maio de 1991, publicado na Gaceta Oficial em 15 d julho de 1991, o depósito foi efetuado em 06 de agosto de 1991.

A República Oriental do Uruguai o ratificou por meio da Lei n. 16.196, de 22 de julho de 1991, publicado no D.O., em 27 de setembro de 1991, o deposito foi efetuado em 06 de agosto de 1991.

\footnotetext{
${ }^{4}$ Cf. GARCIA JÚNIOR, 1997, 2004; GARCIA, 2005; CUNHA, 2017; PEREIRA, 2001; MAZZUOLI, 2001; NASCIMENTO, 2004; SCHUELTER, 2003; PARAGUAY, 2006; GARABELLI, 2004.
} 
Atualmente, o MERCOSUL ampliado é formado pela República da Bolivia e a República do Chile que são Estados Associados por meio do Protocolo de Ushuaia sobre Compromisso Democrático no MERCOSUL, na Cidade de Ushuaia, República Argentina, no dia 24 de Julho de 1998, firmado pelo Governo da Republica Argentina, o Presidente Carlos Saul Menem e o Chanceler Guido Di Tella, Governo da República Federativa do Brasil, Presidente Fernando Henrique Cardoso e o Chanceler Luiz Felipe Lampreia, Governo da Republica do Paraguai, o Presidente Juan Carlos Wasmosy e o Chanceler Ruben Melgarejo Lanzoni, Governo da República Oriental do Uruguai, o Presidente Julio Maria Sanguinetti e o Chanceler Didier Opertti Badan, Governo da República da Bolívia, o Presidente Hugo Banzer e o Chancler Javier Murillo de La Rocha, e Governo da Republica do Chile, o Presidente Eduardo Frei Ruiz e o Chanceler Tagle José Miguel Insulza.

O Peru foi incorporado como Estado Associado pela Decisao CMC n. 39, de 15 de dezembro de 2003. A decisão foi comunicada oficialmente durante a cúpula de presidentes do bloco aduaneiro celebrado, nesse mesmo mês, na República Oriental do Uruguai.

O Protocolo de Adesao da Republica Bolivariana da Venezuela ao MERCOSUL foi assinada em Caracas (Venezuela) no dia 4 de julho de 2006 pelo Presidente Nestor Kirchner da República Argentina, Presidente Luis Inacio Lula da Silva da República Federativa do Brasil, Presidente Nicanor Duarte Frutos da República do Paraguai, Presidente Tabaré Vázquez da Republica Oriental do Uruguai e Presidente Hugo Chavez Frias da República Bolivariana da Venezuela. O projeto de Decreto Legislativo foi aprovado pelo plenário da Câmara dos Deputados em 17 de Dezembro de 2008 e seguiu para votação no Senado Federal Brasileiro. No dia 15 de Dezembro de 2009, o Senado Federal brasileiro aprovou, após votação apertada, por trinta e cinco a vinte e sete votos, o ingresso da Venezuela no MERCOSUL. Em 2006, a Venezuela solicitou a entrada no bloco como Estado-Parte, o que se concretizou em 2012, mas, foi suspensa em dezembro de 2016.

São Estados observadores: México e Nova Zelândia.

O Tratado de Assuncao terá duração indefinida e sua entrada em vigor foi estabelecida para 30 dias após a data de deposito do terceiro instrumento de rafificacao. O Tratado entrou em virgor em 29 de novembro de 1991.

O Tratado de Assuncao consignou duas etapas para a integracao: etapa provisória, encerrada em 31 de dezembro de 1994, que tinha por objetivo dar inicio e 
impulso á formação de um mercado comum; e etapa definitiva, iniciada em $1^{\circ}$ de janeiro de 1995, com a consolidação de uma união aduaneira imperfeita. A fim de facilitar a constituicao do Mercado Comum, os Estados-Parte subscrevem quatro anexos ao Tratado de Assuncao.

Os Estados-Partes consideram que a ampliação das atuais dimensões de seus mercados constitui uma condição fundamental para acelerar seus processos de desenvolvimento econômico com justiça social, sendo a proposta adequada ao movimento internacional que tende a consolidação de grandes blocos econômicos e a necessidade de alcançar uma adequada inserção internacional de seus países. $O$ Tratado também deve ser considerado um novo avanço no esforço tendente ao desenvolvimento em forma progressiva da integração da América Latina, de acordo com o objetivo do Tratado de Montevidéu de 1980.

O Tratado de Assuncao estará aberto a adesão, mediante negociação, dos demais Estados-Membros da Associacao Latino-Americana de Integracao (ALADI), cujas solicitações poderiam ser examinadas pelos Estados-Parte do MERCOSUL, após 5 anos de vigência do mesmo deste Tratado. Não obstante, as solicitações de adesão antes desse prazo podem ser apresentadas pelos Estados-Membros da ALADI desde que não façam parte de outro processo de integração subregional ou de uma associação extraregional.

O Estado-Parte do MERCOSUL que desejar desvincular-se deverá comunicar sua intenção aos demais Estados de maneira espressa e formal e entregar no prazo de 60 dias o documento de denuncia ao Ministerio das Relações Exteriopres do Paraguai que o distribuirá aos demais Estados-Parte.

O Protocolo Adicional ao Tratado de Assuncao sobre a estutura institucional do MERCOSUL, o Protocolo de Ouro Preto, foi adotado no marco da VII Reuniao do Conselho do MERCOSUL realizada na cidade brasileira de Ouro Preto nos dias $16 \mathrm{e}$ 17 de dezembro de 1994 e firmada pelo Presidente da Republica Argentina, Carlos Saul Menem e o Chanceler Guido Di Tella; pelo Presidente da Republica Federativa do Brasil, Itamar Franco e o Chanceler Celso Amorim; pelo Presidente da Republica do Paraguai, Juan Carlos Wasmosy e o Chanceler Luis Maria Ramirez Boettner; e pelo Presidente da Republica Oriental do Uruguai, Luis Alberto Lacalle Herrea e o Chanceler, Sergio Abreu. 


\subsection{PROTOCOLO DE OURO PRETO}

O Protocolo de Ouro Preto foi aprovado pelo Decreto Legislativo n. 188, de 15 de dezembro de 1991, publicado no D.O.U. de 18 de dezembro de 1991 e promulgado pelo Decreto n. 1.901, de 9 de maio de 1996 e publicado no D.O.U, de 22 de novembro de 1996.

Nesse segundo período de transição, que se inicia em $1^{\circ}$ de janeiro de 1005 até novembro de 2006, onde se deve formar plenamente a Uniao Aduaneira, o Protocolo de Ouro Preto consagra a estrutura institucional definitiva do MERCOSUL de acordo com o previsto no Art. 18 do Tratado de Assuncao, dita a normativa que regula os órgãos de administração, o sistema de adoção de decisões e outras questões fundamentais para a vida institucional do MERCOSUL.

O Protocolo de Ouro Preto consta de 53 artigos e um anexo, cujas partes principais dizem respeito a estrutura institucional do MERCOSUL. O Anexo I do Protocolo de Ouro Preto trata do procedimento geral para reclamações junto a Comissao de Comércio do MERCOSUL, do mecanismo de consultas na Comissao do Comércio.

Após inúmeras discussões em torno do aperfeiçoamento do Protocolo de Brasilia, logrou-se finalmente a aprovação de um texto em conformidade dos quatro Estados-Partes e foi assinado pelos Presidentes e Chanceleres de Argentina, Brasil, Paraguai e Uruguai na residência presidencial de Olivos, República Argentina, em 18 de fevereiro de 2002.

\subsection{PROTOCOLO DE OLIVOS}

O Protocolo de Olivos constitiu-se apenas so mais uma aperfeiçoamento do Protocolo de Brasilia, largamento debatido e esperado por vários anos, não é o sistema defintivo, que deve ser consagrado antes de culminar o processo de convergência da tarifa externa comum, situação que haveria de ocorrer em 2006.

Como se sabe, no dia 17 de dezembro de 1991, foi assinado o Protocolo de Brasilia para a Solução de Controversias, em virtude do disposto do Tratado de Assuncao. Assinaram o documento, pela Republica da Argentina Carlos Saul Menem e Guido Di Tella, pela Republica Federativa do Brasil Fernando Collor e Francisco 
Rezek, pela Republica do Paraguai Andréz Rodríguz e Alexis Fritos Vaesken e pela Republica Oriental do Uruguai Luis Alberto Lacalle Herrea e Héctor Gros Espiell.

O documento serviu de base para a solução de novas controvérsias suscitadas durante sua vigtencia e que chegaram aos Tribunais Ad Hoc regulados pelo dito Protocolo.

No entanto, o Protocolo de Olivos, assim como Protocolo de Brasília, não contempla dentro do sistema de solução de controvérsias o controle de legalidade dos atos adotados pelos órgãos do MERCOSUL.

Por meio deste controle de legalidade, os Tribunais teriam a faculdade de pronunciar-se sobre a legalidade das Decisões ditadas pelo Conselho do MERCOSUL, das Resolucoes expedidas pelo Grupo Mercado Comum ou das Diretrizes pronunciadas pela Comissão de Comércio do MERCOSUL.

Não deve-se olvidar que os particulares, pessoas naturais ou jurídicas, que conforme a própria normativa do MERCOSUL podem ser partes em uma controvérsia e que estando interessadas na legalidade dos atos do MERCOSUL, poderiam ter legitimidade ativa para intentar o controle de legalidade por parte dos órgãos jurisdicionais.

Com a entrada em vigor do Protocolo de Olivos, firmado em 18 de fevereiro de 2002, o Protocolo de Brasilia foi derrogado expressamente.

\section{O PROCESSO DE MODERNIZAÇÃO DO PROCESSO DE INTEGRAÇÃO DO MERCOSUL}

Em 12 de maio de 2016, o então Presidente interino da República, Michel Temer no discurso na cerimônia de posse dos novos ministros de Estado, apresentou os Princípios e objetivos da Política Externa Brasileira de seu Governo, no entanto, a sétima diretriz diz respeito ao tema do presente trabalho:

Sétima diretriz: Um dos principais focos de nossa ação diplomática em curto prazo será a parceria com a Argentina, com a qual passamos a compartilhar referências semelhantes para a reorganização da política e da economia. Junto com os demais parceiros, precisamos renovar 0 MERCOSUL, para corrigir o que precisa ser corrigido, com o objetivo de fortalecê-lo, antes de mais nada quanto ao próprio livre-comércio entre seus países membros, que ainda deixa a desejar, de promover uma prosperidade compartilhada e continuar a construir pontes, em vez de aprofundar diferenças, em relação à Aliança para o Pacifico, que envolve três países sulamericanos, Chile, Peru e Colômbia, mais o México. Como disse Enrique 
Iglesias, muito bem observado, não podemos assistir impassíveis à renovação de uma espécie de Tratado de Tordesilhas, que aprofundaria a separação entre o leste e o oeste do continente sul americano. Em relação ao México, será prioritário aproveitar plenamente o enorme potencial de complementaridade existente entre nossas economias e hoje das nossas visões internacionais (Disponível em: $<$ http://www.funag.gov.br/ipri/index.php/noticias/55-repertorio-da-politicaexterna/659-principios-e-objetivos-da-politica-externa-brasileiras. Acesso em: 19 agos. 2017.

Quando se fala em modernização, deve-se pensar justamente em mais e melhor comércio. São duas as prioridades: resgatar o projeto original do MERCOSUL de ser uma zona de livre comércio e, por outro lado, incentivar acordos com outros países e blocos (LIMA, 2015, p. 18).

No primeiro caso, o fato é que o MERCOSUL não se tornou a área de livre comércio que se concebeu no momento de sua gestação. Ainda temos problemas como barreiras não tarifárias, falta de harmonização de regras em diversos setores e segmentos inteiros, como o automotivo, excluídos da livre circulação. Temos que avançar também em regras comuns para temas como compras governamentais, investimentos e serviços, por exemplo. Superar os entraves ainda existentes e desenvolver normas estáveis e comuns são nossas duas prioridades centrais (LIMA.2015, p.18)

No caso das negociações externas, há uma percepção compartilhada entre os sócios fundadores de que a determinação de negociar em conjunto não pode nem deve dificultar a celebração de novos acordos. Esse é um tema cuja discussão deve ser aprofundada (LIMA, 2015, p.18-19).

A literatura acumulada sobre o MERCOSUL, no Brasil e nos países vizinhos, tem abordado as diferentes facetas desse processo de integração - econômica, política, social e jurídica e tem contribuído para uma compreensão razoável do que foi - Mercosul em sua origem, como ele evoluiu ao longo das duas primeiras décadas e sobre quais são seus principais problemas e mudança de paradigmas na política externa do Brasil (Cf. AQUINO, 2001; DIAS, 2010; GARABELLI, 2004; LABRANO, 1998; GONZALES-OLDEKP, 1997; JARDEL; BARRAZA, 1998; MENEM, 1996; ALMEIDA, 1993, 2000, 1998. 1999, 1995, 1996; BOSCOVICH, 1999; CANTERO, 1999; SILVA; RIEDIGER, 2016; LARRAÑAGA, 2002; DESIDERÁ NETO; TEIXEIRA, 2012; GUIMARÃES, 2005; FONSECA JÚNIOR; LEÂO, 1989; PRIETO, 2007; VENTURA, 2013; SILVA; RIEDIGER, 2016; OLIC, 2004; BANDEIRA, 1993). 
A América Latina tentou diversas vezes ao longo da sua história, desde Simón Bolívas (no Congresso de Panamá em 1826) até os nossos dias atuais, intgerar-se para crescer. Porém, o resultado dessas inúmeras tentativas foi, em geral, fraco. Em 1960 a ALAC (Associação Latino-Americana de Livre Comércio) foi um esforço que também representou relativamente pouco na direção do crescimento e do desenvolviento econômico da região. Em 1980, ALADI (Associação Latino-Americana de Integração) foi um pouco mais além, mas também sem atingir os objetivos previstos (LARRAÑAGA, 2002, p. 14).

O MERCOSUL (Mercado Comum do Sul), criado em 1991 dentro do marco da ALADI, removeu barreiras alfandegárias e não-alfandegárias e permitiu um dramático crescimento dos negócios e do volume das mercadorias escoadas através da infraestrutura disponível nos Estados-Parte, Argentina, Brasil, Paraguai e Uruguai (LARRAÑAGA, 2002, p. 14).

A América Latina, em geral, e o MERCOSUL, em particular, devem fazer no seu conjunto, a médio e longo prazo, uma completa racionalização operacional, seguindo o exemplo da União Européia (LARRAÑAGA, 2002, p. 15).

Provavelmente a Argentina continuará conmsiderando o MERCOSUL como Mercado da maior importancia, semse comprometer demasiado com ele até o Brasil definer o que pretende fazer com o bloco, dada dua condição de sócio principal e líder natural (LARRAÑAGA, 2002, p. 63).

Nesses termos:

O Brasil, cujas intenções de liderança regional são conhecidas, e que ademais deseja sere pela comunidade internacional como um potencia media, déverá definer claramente seu papel, para evitar a desrticulação do gruipo, coisa que já tem se manifestado nas atitutudes da Argentina, do Chile e do Uruguai de negociar acordos de livre comércio em forma individual. A liderança regional obriga o Brasil a manter o bllco unido e em paz, para poder ser reconhecido e aceito como interlocutor válido no cenário mundial (LARRAÑAGA, 2002, p. 63-64).

Não obstante, há riscos para o processo de integração, que mais uma vez processo acompanhe a tendência histórica, que indica que cada vez que algum projeto latino-ameriano parece estar bem encaminhado aparecem outros projetos mais dinâmicos que o esvaziam, como tem acontecido com a ALAC, ALADI, Pacto Amazônico e Bacia do Prata, frente a projetos como a Aliança para o Progresso, por 
exemplo, e, que a ALCA absorva o MERCOSUL, ficando este como um acordo comercial sub-regional de importancia secundária (LARRAÑAGA, 2002, p. 66).

Segundo Paulo Roberto de Almeida (2013):

O Mercosul, cujo projeto original de estabelecimento de um mercado comum num prazo relativamente curto nunca chegou a ser implementado, passou por diversas crises, algumas induzidas externamente, outras provocadas por desequilíbrios internos. Seus principais problemas, todavia, estão vinculados às políticas macroeconômicas e setoriais dos seus dois maiores membros, Brasil e Argentina, e ao caráter errático destas. Aos problemas conjunturais registrados em seu itinerário, agregaram-se novas orientações políticas a partir de 2003, trazendo um desvio do foco principal na liberalização comercial para a diversificação política, diversos novos componentes de caráter social, assim como uma falta geral de compromisso com os objetivos prioritários do bloco. Em função dos desequilíbrios e contradições acumulados, não é provável uma correção dos problemas no futuro previsível. Subsiste, portanto, uma indefinição quanto ao seu futuro, que depende, como sempre dependeu, das lideranças políticas (ALMEIDA, 2013, p. 43).

No entanto:

Se o Mercosul quiser ser bem-sucedido, tem de voltar ao básico e cumprir o acordado no Artigo 10 do TA, ou então começar por assumir a responsabilidade de efetuar uma reforma profunda de seus instrumentos constitutivos. A reprodução mimética de um esquema do tipo europeu sempre foi uma quimera do ponto de vista prático, e não existem soluções institucionais indolores que consigam fazer do Mercosul um edifício integracionista - para o qual lhe carecem fundações apropriadas (ALMEIDA, 2013, p.55).

Para Samuel Pinheiro Guimarães (2005):

O Mercosul (e a Argentina e Brasil) enfrentam três desafios de curto prazo no processo de articilação de um papel político autónomo no sistema mundial miltopolar em gestação:

- resistir à absorção na economia e no bloco politico norte-americano que vem avnçando rapidamente, por meio das negociações da Alca, dos TLSs e da dolarização gradual;

- evitar e enfrentar politicamente uma possível intervençao militar externa na Colombia e eventualmene em toda a região amazônica;

- recuperar o controle sobre suas políticas econônicas, domésticas e externas, no momento sob influência direta ou indireta do FMI (e da OMC) (GUIMARÃES, 2005, p. 424-425).

O Mercosul, desde sua criação com o Tratado de Assunção de 1991, surgiu como um projeto econômico-comercial e político-estratégico: ampliar e consolidar a influência regional e internacional do Brasil, por meio do intercâmbio comercial e da 
concertação político-estratégica no nível regional. Naquele momento, visava igualmente aumentar o poder de barganha do Brasil diante da Zona Hemisférica de Livre Comércio (ZHLC), que evoluiria mais tarde para a Área de Livre Comércio das Américas (Alca). A aproximação com a União Europeia também foi perseguida desde o início, tanto como fonte inspiradora para a integração quanto por representar um contrapeso à ZHLC e à Alca (FLORÊNCIO, 2015, p. 8).

Mas, quais são os sintomas da crise do MERCOSUL nos últimos quatros anos? Segundo Abreu e Lima Florêncio (2015), são os seguintes: a perda de prioridade no contexto da política externa brasileira (PEB); resultados comerciais modestos; perfurações da tarifa externa comum (TEC); baixa internalização de decisões do MERCOSUL nos ordenamentos jurídicos internos; e incapacidade de negociar acordos de preferências comerciais/Acordos de Livre Comércio (ALCs) com economias de grande porte. A crise é examinada tendo como parâmetros as mudanças de paradigmas e de posições da Política Externa Brasileira (PEB) e seus efeitos sobre a prioridade do MERCOSUL para o Brasil.

Vejamos as cinco seguintes interpretações destinadas a explicar as causas da crise são estudadas, tendo esse referencial teórico (paradigmas) e empírico (posições políticas):

Primeira interpretação:

Adoção do modelo intergovernamental em lugar da supranacionalidade:

A crise do Mercosul resulta da adoção do modelo intergovernamental (em oposição ao modelo supranacional), que tende a favorecer a "ampliação" do bloco e a impedir seu "aprofundamento". O modelo intergovernamental é inerente ao princípio da autonomia na política externa brasileira (PEB) (FLORÊNCIO, 1990 p. 16).

Segunda interpretação:

Mudança do paradigma americanista/institucionalista pragmático (FHC) para o globalista/autonomista (Lula/Dilma):

A crise do Mercosul se explica pela passagem do paradigma americanista/institucionalista pragmático para 0 paradigma globalista/autonomista na PEB. As reformas econômicas e a estabilização inauguradas em meados dos anos 1990 no governo FHC abriram caminho para que $\circ$ Brasil ganhasse competitividade e pudesse beneficiar-se do acelerado crescimento da economia internacional e do boom na demanda de matérias primas por parte da China na primeira década do século XXI. Essa 
conjuntura favorável permitiu que o país se projetasse como uma grande economia emergente. A crise econômica internacional de 2008/2009 abriu espaço para que novas instituições (como o G20 financeiro) desempenhassem papel relevante na nova governança global. Esse quadro favorecia maior presença internacional do país. Nesse contexto, o Presidente Lula empenhou-se em projetar a imagem do Brasil como um "major global player", priorizando o paradigma globalista, e, como consequência, a América Latina se eclipsou no âmbito da PEB. Assim, essa transição do paradigm americanista/institucionalista pragmático $(\mathrm{FHC})$ para o globalista/autonomista (Lula/ Dilma) reduziu a importância do Mercosul e explica sua atual crise (FLORÊNCIO, 1990, p 21).

Terceira interpretação:

Criação da UNASUL como fonte de fragilização do MERCOSUL e de politização da Iniciativa para a Integração da Infraestrutura Regional Sul-americana (IIRSA):

\begin{abstract}
A crise do Mercosul resulta da inflexão na política brasileira para a América do Sul, com a criação, em 2004, da União Sul-Americana de Nações (Unasul). Ao mesmo tempo em que a mudança em direção ao paradigma globalista/autonomista reduzia a prioridade do Mercosul no contexto internacional, no plano regional a Unasul tinha efeito semelhante, pois absorvia o foco da nossa estratégia regional, em detrimento do Mercosul. Embora a Unasul fosse destinada a amalgamar os dois processos subregionais de integração - Mercosul e CAN - na realidade teve como resultado concreto fragilizar o Mercosul e politizar a IIRSA (FLORÊNCIO, 1990, p. 27).
\end{abstract}

Quarta interpretação:

Modelo atípico do MERCOSUL, ausência de um padrão hub and spoke:

A crise do Mercosul resulta de um padrão de comércio intrabloco atípico: o sócio maior revela incapacidade de exercer um papel que efetivamente beneficie os sócios menores e não existe uma relação de "hub and spoke"13 entre seus membros. Em claro contraste com outras experiências exitosas de integração, o Brasil é superavitário no intercâmbio com o Paraguai e, em diversos anos, com o Uruguai. Além disso, 0 mecanismo destinado a reduzir assimetrias - Focem - é insuficiente, composto por projetos mal estruturados e com viés mais político que técnico (FLORÊNCIO, 1990, p. 32).

Quinta interpretação:

A crise seria resultante do divórcio entre a PEB e a Argentina na era Menem/Fernando Henrique e da confluência de políticas intervencionista nas presidências do casal Kirchner e de Lula - segundo mandato/Dilma:

As marcantes diferenças nas linhas de política externa durante os mandatos de Menen, na Argentina, e de Cardoso, no Brasil, ao longo da década de 1990, aliadas à adoção de um modelo econômico intervencionista 
e heterodoxo prevalecente nos dois países, durante as presidências do casal Kirchner, na Argentina, e de Lula-Segundo mandato/Dilma, no Brasil, a partir dos anos 2000, explicam as crises no Mercosul (FLORÊNCIO, 1990, p. 3637).

O marco teórico, portanto, aponta para o forte poder explicativo das interpretações 2, 3 e 4, a saber:

[...] as interpretações um e dois, ou seja, a passagem do paradigma americanista/institucionalista pragmático $(\mathrm{FHC})$ para o globalista/autonomista (Lula) e a mudança de rumos concretos na PEB - prioridade para a Unasul, politização da IIRSA e fragilização do Mercosul - condicionam e explicam a crise recente do processo de integração. Contribui ainda para explicar a crise a interpretação quatro, ou seja, o caráter atípico do bloco, em que o sócio maior é superavitárioccom os parceiros menores e inexiste uma clara relação hub and spoke (FLORENCIO, 2015, p.46).

\section{CONCLUSAO}

Duas questões gerais nortearam este trabalho: a primeira diz respeito ao fato de que é cediço que um dos principais propósitos hoje é modernizar o modelo de integração regional. O Mercado Comum do Sul (MERCOSUL) completou vinte seis anos e devemos ajustá-lo à atual realidade; a segunda questão consistiu em rever a literatura acumulada sobre o MERCOSUL que tem abordado as diferentes facetas desse processo de integração - econômica, política, social e jurídica e tem contribuído para uma compreensão razoável do que é MERCOSUL.

Com vistas a esse fim, percorreu-se, do ponto de vista do marco de referência e conceitual, a bibliografia de relevância já tornada pública em relação ao tema de estudo, bem como os diplomas legais do MERCOSUL, que auxiliaram na construção teórica e ao mesmo tempo a reconstrução crítica dos seus fundamentos.

Por conseguinte, o presente trabalho chegou aos seguintes resultados:

1. Em relação aos objetivos:

1.1 Em relação ao objetivo geral que é "analisar criticamente o processo de modernização do modelo de integração do Mercado Comum do Sul (MERCOSUL)", chegou-se à conclusão de que a literatura acumulada sobre o MERCOSUL, no Brasil e nos países vizinhos, tem abordado as diferentes facetas desse processo de integração - econômica, política, social e jurídica e tem contribuído para uma compreensão razoável do que foi o Mercosul em sua origem, como ele evoluiu ao 
longo das duas primeiras décadas e sobre quais são seus principais problemas e mudança de paradigmas na política externa do Brasil;

1.2. Em relação ao primeiro objetivo específico que é " avaliar a formação da ALALC e ALADI nos anos sessenta", conclui-se que a ALALC e ALADI, significam um importante antecedente do MERCOSUL, que desembocaram diretamente na formação do bloco, constituem dois cimentos deste processo de integração;

1.3. Em relação ao segundo objetivo específico que é "identificar as características positivas e negativas do Tratado de Assunção, Protocolo de Ouro Preto, Protocolo de Olivos e demais diplomas legais e suas eficácias", verifica-se que são importantes instrumentos marcos normativos para a criação, desenvolvimento e reconstrução do MERCOSUL, e, conclui-se que todos esses trarados e acordos se encontram dentro do marco da Associação Latino-Ameriano de Integração (ALADI) que permite a participação a todos os Estados-Parte e associados ao MERCOSUL para a plena integração.

1.3 Finalmente, em relação ao terceiro objetivo específico que é "analisar o processo de modernização do processo de integração do MERCOSUL", concluiu-se no qual há pelo menos cinco interpretações com forte poder explicativo das causas da crise, com vistas a formulação e concretização de um conjunto de medidas de diversas ordens para acelerar o processo de modernização do modelo de integração do MERCOSUL.

2. Em relação à hipótese que é "por considerar que o MERCOSUL se encontra no estágio de União Aduaneira (imperfeita), há necessidade de analisar criticamente o seu processo de modernização: ajustes à realidade em que se vive, resgate o projeto inicial e incentivo aos acordos com outros Estados e blocos". Corrobora-se a hipótese.

3. A conclusão final deste trabalho é a seguinte:

O modelo escolhido pelo MERCOSUL adotou um modelo que se caracterizou pelo regionalismo aberto ou regiinalismo para a globalização, institucionalidade governamental e concepção estadocêntrica.

Se o MERCOSUL quiser ser bem-sucedido, tem de voltar ao básico e cumprir o acordado no Artigo $1^{\circ}$ do Tratado de Assunção, ou então começar por assumir a responsabilidade de efetuar uma reforma profunda de seus instrumentos constitutivos. A reprodução mimética de um esquema do modelo da União Europeia sempre foi uma quimera do ponto de vista prático, e não existem soluções institucionais que consigam fazer do MERCOSUL um edifício integracionista. 
Por fim, o Brasil deve manter uma posição de liberança sub-regional, privilegiando o MERCOSUL e estabelecendo novas alianças e buscando um papel mais preponderante no sistema internacional.

Portanto, há razões suficientes para reavaliar as políticas extenas no Brasil e da Argentina e elaborar estratégias para a construção em favor de uma política externa do MERCOSUL Não há negociação bem-sucedida sem reciprocidade. Negociar é justamente isso: saber ceder em troca de algo.

4. Para futuras investigações recomenda-se: ampliar a revisão da literatura e realizar um estudo comparado do MERCOSUL comos demais blocos de integração regional. No entanto, o exame destas implicações, ultrapassa os limites deste trabalho.

\section{REFERÊNCIAS}

ALMEIDA, P. R. O MERCOSUL no contexto regional e internacional. Sao Paulo: Aduaneiras, 1993.

L'Harmattan, 2000.

- Le Mercosul: un marché commum pour l'Amérique du Sud. Paris: . Mercosul: fundamentos e perspectivas. São Paulo: LTr, 1998.

. Mercosul, Nafta, Alca: a dimensão social (Org. com Yves Chaloult). São Paulo: LTr, 1999).

. L'intégration latino-americaine et le Mercosul. Paris: Ambassade du Brésil, 1995.

. MERCOSUR y Unión Europea. In: COUFFIGNAL, G.; DE LA REZA, G. A. (Eds.). Los procesos de integración en América Latina. Stockholm: University of Stockholm, 1996, p. 113-130.

. MERCOSUL: do otimismo à resignação. Boletim de Economia e Política Internacional - BEPI, n. 16, Jan./Abr. 2014

AQUINO, Ricardo Caballero. MERCOSUR e Integración: fantasía económica, realidad política. in: La Revista Crítica. Asunción - Paraguay. Año XI, no 17, Mayo 2001. p. 1922.

BANDEIRA, Moniz. Estado nacioal e política internacional na América Latina: o continunete nas relações Argentina-Brasil (1930-1992). São Paulo: Ensaio, 1993.

BOSCOVICH, Nicolás. Geoestrategia para la integracion regional. Buenos Aires, Ciudad Argentina, 1999. 
BOHLKE, Marcelo. Integração regional \& autonomia do seu ordenamento jurídico. Curtiba: Juruá, 2006.

CANTERO, Carlos Marcial Russo. El MERCOSUL ante la necesidad de organismos suoracionales. Asuncion - Intercontinental, 1999.

CUNHA, Paulo Ferreira da Cunha. Direito internacional: raízes e asas. Belo Horizonte: Fórum, 2017.

DESIDERÁ NETO; TEIXEIRA. Perspectivas para la integrción de América Latina. Brasília, DF: IPEA: CAF, 2012.

DIAS, Manoel Coracy Saboia. Internalização, vigência e eficácia das normas do MERCOSUL no ordenamento jurídico brasileiro. 2006. 209 f. Travalho de Conclusão de Curso (Bacharelado em Direito) - Faculdade da Amazônia Ocidental, Rio Branco. Rio Branco.

DOMINGUES, Juliana Oliveira; OLIVEIRA, Cristina Godoy Bernardo de. Direito econômico internacional. Curitiba: InterSaberes, 2017.

DROMI, Roberto; EKMEKDJIAN, Miguel A.; RIVERA, Julio C. Derecho comunitario: sistemas de integración; régimen del MERCOSUR. 2 ed. Buenos Aires: Ciudad Argentina, 1996.

FERREIRA, Ana Paula Lopes; MERCHER, Leonardo. História política comparada da América Latina. Curitiba: InterSaberes, 2015.

FINKELSTEIN, Cláudio. O processo de formação de Mercados de bloco. São Paulo: IOB - Thomson, 2003.

FLORÊNCIO, Sérgio Abreu e Lima. Trajetória do Mercosul e Mudança de Paradigmas da Política Externa Brasileira: possíveis interpretações para a crise do bloco. Boletim de Economia e Política Internacional, BEPI n. 19, Jan./abr. 2015. p. 59-73.

FONSECA JÚNIOR., Gelson; LEÃO, Valdemar Carneiro (Orgs.). Temas de política externa brasileira. Brasília: Fundação Alexandre de Gusmão/Editora Ática, 1989.

GARCIA JUNIOR, Armando Álvares. MERCOSUL: legislação fundamental especifica. Edição em Português e Espanhol. São Paulo: Jurídica Brasileira, 1997.

2007.

. ALCA: a Àrea de Livre Comércio das Américas. 2 ed. São Paulo: Aduaneiras, . Direito Internacional: questões atuais. 2. ed. São Paulo: Aduaneiras, 2004.

GARCIA, Eugenio Vargas. Cronologia das Relações Internacionais do Brasil. Rio de Janeiro: Contraponto; Brasilia - DF - Fundacao Alexandre de Gismao, 2005.

GARRABELI, Carlos A. González. Procesos de integracíon: MERCOSUR e soluções de controvérsias. Asunción: CIDSEP-UC, 2004. 
GUIMARÃES, Samuel Pinheiro. Desafios brasileiros na era de gigantes. Rio de Janeiro: Contraponto, 2005.

GONZALEZ-OLDEKOP, Florencia. La integracion y sus instituciones. Bienos Aires, Ciudad Argentina, 1997).

JARDEL, Silvia, BARRAZA, Alejandro. Mercosur aspectos jurídicos y econômicos. Buenos Aires, Ciudad Argentina, 1998.

LABRANO, Roberto Ruiz Diaz. MERCOSUR: integración y derecho. Buenos Aires: Intercontinental Editora, 1998.

LARRAÑAGA, Félix Alfredo. Desenvolvimento econômico do Cone Sul: o sistema logístico sub-regional. São Paulo: Aduaneiras, 2002.

LEAL, Rosemiro Pereira et al. Curso de Direito economico-comunitario. Teoria do direito e tecnica processual nos blocos economicos. Porto Alegre - Sintese, 2001.

LIMA, Sérgio Eduardo Moreira. A Política Externa Brasileira. Palestra de abertura da V Conferência sobre Relações Exteriores (CORE), na Universidade da Amazônia (UNAMA), Belém, 9 de novembro de 2016. Cadernos de Política Exterior. Brasília, DF: Instituto de Pesquisa de Relações Internacionais. - v. 2, n. 4 (dez. 2016).

MACHADO, José Luiz. Blocos econômicos no panorama mundial: análise geográfica e econômica. Curitiba: InterSaberes, 2012.

MAZUOLLI, Valerio de Oliveira. Tratados internacionais. São Paulo: Juarez de Oliveira, 2001.

MENEM, Carlos Saúl. What is MERCOSU? Buenos Aires, Ciudad Argentina, 1996).

MERCOSUL: Legislação e Textos Básicos/Ministério das Relações Exteriores e Comissão Parlamentar Conjunta do Mercosul - Seção Brasileira. Senado Federal [Brasília]: (1996). 2 ed.

MERCOSUL: Textos básicos/Paulo Roberto de Almeida - Coordenador - [Brasília]: Fundação Alexandre de Gusmão, 1992.

NASCIMENTO, Maria Luiza Justo. A incorporação das normas do MERCOSUL aos ordenamentos jurídicos dos Estados-membros. Curitiba: Juruá, 2004.

OLIC, N. B. Geopolítica da América Latina. São Paulo: Moderna, 1992.

PARAGUAY. Corte Suprema de Justicia. Instrumentos normativos del MERCOSUR. Asunción: Corte Suprema de Justicia: División de Investigación, Legislación y Publicaciones del Centro Internacional de Estudios Judiciales, 2006.

PEREIRA, Ana Cristina Paulo. Direito institucional e material do MERCOSUL. Rio de Janeiro - Lumen Juris, 2001. 
PRIETO, Félix Gerardo Ibarra. Soberanía y supranacionalidad en el proceso de integración del Mercosur. Dissertação (Mestrado em Relações Internacionais), Universidad Autónoma de Asunción, Asunción, PY: 2007.

SILVA, André Luiz Reis da; RIEDIGER, Bruna Figueiredo. Política externa brasileira: uma introdução. Curitiba: InterSaberes, 2016.

SCHUELTER, Cibele Christiane. Tratados internacionajus e a lei interna brasileira: o problema da hierarquia das normas. Florianópiolis: OAC - SC Editora, 2003.

SEITENFUS, Ricardo. Relações Internacionais. 2.ed. Barueri, SP: Manole, 2013.

TEMER, Michel. Princípios e objetivos da Politica Externa Brasileira. Disponível em: <http://www.funag.gov.br/ipri/index.php/noticias/55-repertorio-da-politica externa/659principios-e-objetivos-da-politica-externa-brasileira>. Acesso em: 19 agos. 2017.

VENTURA, Deisy. As assimetrias entre o MERCOSUL e a Uniao Europeia: os desafios de uma associação inter-regional. Barueri, SP - Manolo, 2003. 